\title{
(O) CPes: Medicine \\ VALIDATION OF SIGNIFICANT PROTEIN MARKERS FROM THE \\ PLASMA OF SEVERE DENGUE INFECTED ADULT PATIENTS USING SELECTED REACTION MONITORING ASSAY
}

\begin{tabular}{l|}
\hline $\begin{array}{l}\text { Tundwal Vijay } \\
\text { Kumar }\end{array}$ \\
\hline Somveer \\
\hline Satyaveer Singh \\
\hline Gunhawat \\
Manisha* \\
\hline Gahlot Narendra \\
Kumar \\
\hline Kochar Aditya \\
\hline
\end{tabular}

Tundwal Divyanshi

Kochar Sanjay

Kumar
Associate Professor, Department Of Medicine, S.p. Medical And P.b.m. Associated Group Of Hospitals, Biknaer (rajasthan)

Resident, Department Of Medicine, S.p. Medical And P.b.m. Associated Group Of Hospitals, Biknaer (rajasthan)

Resident, Department Of Medicine, S.p. Medical And P.b.m. Associated Group Of Hospitals, Biknaer (rajasthan)

Resident, Department Of Medicine, S.p. Medical And P.b.m. Associated Group Of Hospitals, Biknaer (rajasthan). ${ }^{*}$ Corresponding Author

Assistant Professor, Department Of Medicine, S.p. Medical And P.b.m. Associated Group Of Hospitals, Biknaer (rajasthan)

Medical Student, Department Of Medicine, S.p. Medical And P.b.m. Associated Group Of Hospitals, Biknaer (rajasthan)

Medical Student, Department Of Medicine, S.p. Medical And P.b.m. Associated Group Of Hospitals, Biknaer (rajasthan)

Senior Professor, Department Of Medicine, S.p. Medical And P.b.m. Associated Group Of Hospitals, Biknaer (rajasthan)

\section{ABSTRACT}

Background: Infection with dengue virus (DENV) causes a spectrum of clinical manifestations ranging from mild dengue fever (DF) to the potentially lethal dengue hemorrhagic fever (DHF) and dengue shock syndrome (DSS). Dengue is endemic to the tropical and sub-tropical regions of the world, which are home to over half the population of the world as well as being popular tourist destinations

Aim : To study about information of the pathogenesis and clinical profile of dengue virus and Validation of significant protein markers of dengue infected adult patients using selected reaction monitoring assays.

Material \&Methods :This study was conducted in Department of Medicine, Sardar Patel Medical College, Bikaner from July 2017 to December 2018 . Total 26 cases with features of dengue illness along with positive dengue serology in this duration were admitted in hospital. This was a hospital based study.

Results : Proteomic analysis in severe dengue patients (DHF/DSS) shows down regulation of three significant proteins CD-44 antigen, complement component C8 beta chain and leucine-rich alpha-2-glycoprotein as compared to healthy controls. According to dengue agglutination test, $100 \%$ cases had IgM positive while $69.2 \%$ cases had NS1 positive. No case had IgG positive. Mean age in DHF group was 30.4812.58 and in DSS group mean age was 25.00 12.39 years and this difference was found statistically insignificant ( $\mathrm{p}>0.05$ ). Most common clinical manifestation was fever, abdominal pain and myalgia (100\%) while rash was present in $96.2 \%$, vomiting and headache were present in $92.3 \%$ cases each and least common clinical manifestation was retro-orbital pain (88.5\%). Gum bleeding, epistaxis and petechiae were found in most cases.According to sensorium $96.2 \%$ cases were found normal and $3.8 \%$ cases were altered sensorium.According to outcome, 20 cases were cured successfully while 6 cases discharge on request. Patients were on telephonically follow up for one week, there was no mortality.

Conclusion : In present study revealed that validating 26 serum samples used for optimization by using selected reaction monitoring. Three significant proteins, CD44 Antigen, Complement component C8 beta chain, Leucine-rich alpha-2-glycoprotein are downregulated in severe dengue (DHF/DSS) patients as compared to healthy controls. These are predictive biomarkers of severe dengue fever (DHF/DSS).

\section{KEYWORDS : DHF, DSS, Proteomics, DENV}

\section{INTRODUCTION}

Infection with dengue virus (DENV) causes a spectrum of clinical manifestations ranging from mild dengue fever (DF) to the potentially lethal dengue hemorrhagic fever (DHF) and dengue shock syndrome (DSS) ${ }^{1}$. In humans, the major cellular targets of dengue appear to be dendritic cells of the skin, macrophages and monocytes ${ }^{2}$.

Dengue fever was first reported in 1780, when Benjamin Rush described this condition as "Break bone fever" because it causes such severe aches in the joints. Dengue virus (DENV) is a mosquito-borne single-stranded RNA virus member of genus Flavivirus of the family Flaviviridae. It is mosquito borne viral infection with four serotypes, causing dengue fever (DF), dengue hemorrhagic fever (DHF), and dengue shock syndrome (DSS). It is estimated that worldwide more than 50 million infections occur each year including 500,000 hospitalizations for dengue hemorrhagic fever, mainly among patients with the case fatality rate exceeding $5 \%$ in some areas ${ }^{3}$. Dengue has been identified as one of the neglected tropical diseases by WHO as mentioned in their report on neglected tropical diseases $(2010)^{4}$. Approximately 1.8 billion (more than $70 \%$ ) of the population at risk for dengue worldwide live in Member States of the WHO South East Asia Region (SEAR) and Western Pacific Region, which bear nearly $75 \%$ of the global disease burden due to dengue ${ }^{5}$.

\section{MATERIALAND METHODS}

This study was conducted in Department of Medicine, Sardar Patel Medical College, Bikanerfrom July 2017 to December 2018. Total 26 cases with features of dengue illness along with positive dengue serology in this duration were admitted in hospital.

Type of the Study: Hospital based comparative cross sectional study. Selection criteria for dengue illness

\section{Inclusion Criteria}

- Adults $\geq 18$ years who were serologically positive with dengue illness were included.

- Malaria infection was rule out by microscopy examination and RDT.

- Those willing to provide written informed consent and comply with protocol requirement. 


\section{EXCLUSION CRITERIA}

- Other concomitant illness like malaria, enteric fever, chikungunya etc. judged by history and physical examination and investigations based.

- Subjects unwilling to consent for the study.

\section{Diagnosis of dengue infection}

The diagnosis of DF patients was primarily based on clinical examination and was confirmed by using kit-based solid phase dengue $\mathrm{NS} 1 \mathrm{Ag}+\mathrm{Ab}$ Duo test immuno-chromatographic assay, one step assay designed to detect both dengue virus NS1 antigen and differential IgM/IgG antibodies to dengue virus in human blood (RapiGEN BIOCREDIT Dengue NS1Ag+Ab Duo Test, Korea) as per manufacturer's instructions.

\section{Proteomic analysis was done in following manner:}

- Comparative proteomic analysis of dengue and controls (2DE, 2D-DIGEand QTOF LCMS/MS

- Proteins networks and functional analysis

- Multivariate statistical analysis

\section{Proteomic Analysis}

Amongst total 26 enrolled cases of severe dengue (DHF/DSS), $(n=26)$ were sent to IIT Bombay for proteomics analysis. A comparison between severe dengue (DHF/DSS) compared to Healthy controls (HC). HC were defined as adult of same age group, environment, race and disease free.

\section{Plasma separation at PBM Hospital Bikaner}

Blood samples were drawn in EDTA vials from all adults included in this study after written and informed consent. Immediately after blood collection, the tubes were kept on ice for 30 minute and then centrifuged at $2000 \mathrm{rpm}$ for 10 minute. After centrifugation blood samples was divided in two parts upper yellow color liquid which was plasma and lower red color were cells and plasma was collected in sample aliquot and stored at $-80^{\circ} \mathrm{C}$.

\section{Performed at Indian Institute of Technology, Bombay, Powai, Mumbai as following:}

\section{Sample preparation and depletion of abundant protein}

Crude plasma was diluted four times with phosphate buffer $(\mathrm{pH} 7.4)$ and subjected to gentle sonication with the following settings: 8 cycles of $5 \mathrm{sec}$ pulse; $30 \mathrm{sec}$ gap in between; at 25\% amplitude using Sonics vibra cell sonicator. 22 proteins contribute to approximately $99 \%$ of the protein content in serum and plasma ${ }^{77}$. With the use of depletion column, these high abundant proteins could be removed for the detection of low abundant proteins. In this manner, two high abundant proteins (albumin and IgG) were removed using Albumin \&IgG Depletion spin trap (GE Healthcare- 28-9480-20) as per manufacturer's instruction.

\section{Protein extraction by TCA-acetone precipitation}

Following depletion, protein extraction was carried out using TCAacetone precipitation. Slight modifications to the protocols ${ }^{6}$ were made for extraction from the plasma samples. In brief, dilution of the samples was carried out using chilled acetone containing $10 \% \mathrm{w} / \mathrm{v}$ of TCA. The mixture was vortexed for 30 seconds and incubated at $-20^{\circ} \mathrm{C}$ for 16 hours. This mixture was then centrifuged at $15000 \mathrm{rpm}$ for 30 minutes at $4^{\circ} \mathrm{C}$. To the pellet $1 \mathrm{ml}$ of chilled acetone was added to wash away the remaining TCA and also to the supernatant to completely precipitate the protein. This was followed by vortexing for 30 seconds and incubation at $-20^{\circ} \mathrm{C}$ for $30 \mathrm{mins}$. The tubes were then centrifuged at $15000 \mathrm{rpm}$ for $20 \mathrm{mins}$ at $4^{\circ} \mathrm{C}$. The pellet fraction was washed once more as described and dissolved in Rehydration buffer (RHB) [2 M thiourea, $8 \mathrm{M}$ of urea, $2 \%(\mathrm{w} / \mathrm{v})$ CHAPS, $0.002 \% \mathrm{BPB}$ and $0.5 \%(\mathrm{v} / \mathrm{v})$ carrier ampholyte]. Sample clean up was performed using $2 \mathrm{D}$ clean-up kit by GE Healthcare as per manufacturer's instructions to remove salts, detergents, nucleic acids and lipids that may interfere in the downstream processes.

\section{STATISTICALANALYSIS}

Collected data were transferred into SPSS version 17.0 and were analyzed with the help of frequency tables, percentage and appropriate statistical test wherever applicable.

\section{Management}

Cases were managed as per standard treatment protocol put forward by WHO (2009).

\section{RESULTS}

The present study was conducted in the Department of Medicine, S.P. Medical College and P.B.M. Associated Group of Hospitals, Bikaner.

In present study, $100 \%$ cases had IgM positive while $69.2 \%$ cases had NS1 positive. No case had IgG positive. Mean age in DHF group was 30.4812 .58 and in DSS group mean age was 25.0012.39 years and this difference was found statistically insignificant $(\mathrm{p}>0.05)$.

Most common clinical manifestation was fever, abdominal pain and myalgia $(100 \%)$ while rash was present in $96.2 \%$, vomiting and headache were present in $92.3 \%$ cases each and least common clinical manifestation was retro-orbital pain $(88.5 \%)$. Gum bleeding was present in $90.5 \%$ cases, epistaxis was present in $66.7 \%$ petechiae was present in $52.4 \%$, hematuria was present in $33.3 \%$ cases, hematemesis was present in $14.3 \%$ of cases and melena was present in $9.5 \%$ cases while in DSS group, $100 \%$ cases had gum bleeding, $80 \%$ cases had epistaxis, $60 \%$ cases had petechiae, $40 \%$ each cases had hematemesis and hematuria. Purpura and subconjunctival haemorrhage was not found in any case $(\mathrm{p}>0.05)$.

On day 1, mean haemoglobin in DHF group was 7.560.34 and in DSS group it was $8.320 .48 \mathrm{mg} / \mathrm{dl}(\mathrm{p}<0.01)$, on day 2 , mean haemoglobin in DHF group was 7.680.31 and in DSS group it was $8.52045(\mathrm{p}<0.01)$, on day 3 mean haemoglobin was $7.961 .40 \mathrm{mg} / \mathrm{dl}$ and in DSS group it was $8.760 .41(\mathrm{p}<0.001)$ while on day 4 , mean haemoglobin in DHF group was 8.180.13 and in DSS group it was $8.970 .43(\mathrm{p}<0.001)$.

Asictes was present in 15 cases and out of them 13 and 2 cases belonged to DHF and DSS group respectively, bilateral pleural effusion was found in total 13 cases and out of them 10 and 3 cases belonged to DHF and DSS groups respectively, GB wall edema was present in 5 cases and out of them 4 and 1 case belonged to DHF and DSS group respectively while hepatomegaly was found in 2 cases and they both belonged to DHF group ( $p>0.05$ in all). According to outcome, 20 cases were cured successfully while 6 cases discharge on request. Patients were on telephonically follow up for one week, there was no mortality.

Proteomic analysis in severe dengue patients (DHF/DSS) shows down regulation of three significant proteins CD-44 antigen, complement component C8 beta chain and leucine-rich alpha-2-glycoprotein as compared to healthy controls.

\section{DISCUSSION}

Dengue is endemic in SEAR (South East Asia Region) including India. In India, dengue epidemics are becoming more frequent. Every year cases are spreading to newer geographical area. All four dengue virus serotype have been isolated from different parts of the country. India contributed $6-9 \%$ of total cases in SEAR countries between 2009 and 2011, which has increased to $19 \%$ in 2013. Dengue is one disease entity with different clinical presentations and often with unpredictable clinical evaluation and outcome.

The mechanisms that trigger transition from mild DF to more life threatening DHF are poorly understood, hampering early classification of dengue patients who will progress to DHF. This not only delays treatment but frequently result in the over hospitalisation of the patients, contributing significantly to the financial burden imposed by dengue ${ }^{7,8}$. The availability of reliable markers that predict DHF during the early stage of infection could be useful in triaging patients for management.

Out of total 26 cases, $21(80.7 \%)$ had dengue haemorrhagic fever (DHF) while 5 (19.3\%) cases had dengue shock syndrome (DSS). The results were similar to study conducted by China et al ${ }^{9}$ where a higher percentage of cases had DHF as compared to DSS. All the cases (26) were IgM positive while 18 cases were NS1 positive. No case was found to be IgG positive.

In the present study, majority (100\%) of the patients presented with fever, abdominal pain and myalgia. The other symptoms observed were rash (96.2\%), vomiting and headache (92.3\% each), retro- orbital pain $(88.5 \%)$. It was similar to study conducted by Kumar et $\mathrm{al}^{10}$ which showed fever (85\%), headache $(73 \%)$, arthralgia (52\%), retro orbital pain $(70 \%)$, abdominal pain $(54 \%)$, rash $(16 \%)$, vomiting $(70 \%)$ and diarrhoea (19\%). The symptoms observed in the study by Laulet al ${ }^{11}$ were fever $(100 \%)$, headache $(87 \%)$, bodyache $(86 \%)$, retro orbital pain $(58 \%)$, rashes $(21 \%)$. 
In our study, among the bleeding manifestations most common was gum bleeding with $92.3 \%$ cases followed by epistaxis $(69.2 \%)$, petechaie $(53.8 \%)$, hematuria $(34.6 \%)$, hematemesis $(19.2 \%)$, melena $(7.7 \%)$ while no cases had purpura and subconjuctival haemorrhage. All these parameters had an insignificant correlation when we compared them between DHF and DSS groups ( $>0.05)$. The results were in accordance to Zhang et $\mathrm{al}^{12}$ study where the gum bleeding was the most common bleeding manifestation followed by epistaxis.

Haemoglobin levels in dengue fever corresponds to hematocrit level and hemoconcentration. There was fall in $\mathrm{Hb}$ in patients with bleeding manifestation. In this study we observed the pattern of $\mathrm{Hb}$ level over the entire duration of admission. Mean hemoglobin levels on day 1 of admission (day 3-4 of fever) were found to be 8.320 .48 in DSS group while it was $7.560 .34 \mathrm{mg} / \mathrm{dl}$ in DHF group $(\mathrm{p}<0.01)$. The mean haemoglobin values increased on subsequent days in both DSS and DHF groups with the values being 8.970 .43 and 8.180 .13 respectively $(p<0.001)$ on day 4 of admission. The mean values in DSS patients were higher on all the days as compared to DHF patients. The difference became statistically significant on day 3 and 4 of admission. Hemoglobin levels were found to be lower during initial days of admission and was significantly lower in DHF group of diseased population. The reason was hemodilution due to plasma leakage and hemorrhagic tendencies in DHF whose maximum incidence is during 4-6 day of fever. Similar results were observed in Mehrotraet $\mathrm{al}^{13}$ study who showed that on day 4 of fever $52.78 \%$ patients had normal haemoglobin which increased to $57.14 \%$ on day 7 and $60 \%$ on day 10 of fever.

In the present study, ascites was the most common USG finding with $57.7 \%$ cases followed by bilateral pleural effusion $(50 \%)$, GB wall edema (19.2\%) and hepatomegaly (7.7\%). Ascites was more common in DHF patients while pleural effusion was more common in DSS. The results were in accordance to the study by Khurramet al ${ }^{14}$ who observed that ascites was the most frequently noted USG finding followed by pleural effusion and GB wall edema.

In our study, according to outcome, $20(76.9 \%)$ cases were cured successfully while $6(23.1 \%)$ cases were discharged on request. Patients were on follow up telephonically for one week, there was no mortality.

In our study, we validated the human serum proteome alterations that occurred due to severe dengue fever and had altered expression levels associated with coagulation and complement cascade, and inflammation-mediated acute phase signalling. To the best of our knowledge, we report here the first comprehensive analysis validating the significant protein markers seen in severe dengue fever patients in Bikaner (North-west Rajasthan). We have optimized a number of differentially expressed serum proteins using Selected Reaction Monitoring Assay and performed analysis validating the proteomic markers in severe dengue patients. Three significant proteins CD44 antigen, Complement component C8 beta chain, Leucine-rich alpha-2glycoprotein were analysed in our study. CD44 is an adhesion molecule for extracellular matrix proteins and is a cytotoxicity marker present on activated NK cells. Complement component $\mathrm{C} 8$ beta chain is a constituent of the membrane attack complex (MAC) that plays a key role in the innate and adaptive immune response by forming pores in the plasma membrane of target cells. Leucine-rich alpha-2glycoprotein is a secretory type 1 acute phase protein whose expression is upregulated by the mediators of acute phase response and its level increases during infections and cancer.

We observed that these markers are down-regulated in the sera of severe dengue patients (DHF/DSS) as compared to healthy controls that samples were taken from same institution for proteomic analysis of severe dengue patients ${ }^{15}$ because of fold change less $<1$. Fold change values were $0.987409,0.987244$ and 0.984124 in CD44 antigen, Complement component $\mathrm{C} 8$ beta chain $(\mathrm{CO} 8 \mathrm{~B})$ and Leucine-rich alpha-2-glycoprotein (A2GL) respectively. Thus, it was observed that proteins CD44 antigen, Complement component C8 beta chain, Leucine-rich alpha-2-glycoprotein are predictive biomarkers of severe dengue fever(DHF/DSS).

Chun-Yu-Lin et $\mathrm{al}^{16}$ study observed that highly circulating level of viral protein NS1 is indicative of disease severity. Its exposure decreased the expression of CD44 in differentiating endothelial cells impairing the interity of vessel like structures. This study supported our result of downregulation of CD44 antigen.
In study by Flores-Mendoza et $\mathrm{al}^{17}$, it was observed that IL 10 and $\operatorname{socs} 3$ are predictive biomarkers of DHF while Manchala et $\mathrm{al}^{18}$ showed the prognostic role of apolipoprotein A-I (APO A-I) in dengue fever. Jadhav et $\mathrm{ll}^{15}$ found significant elevation in IL-1 RA, IL-7, TNF- $\alpha$, MCP1-MCAF and MIP-1 $\beta$ levels in DHF patients. Mapalagamageet $\mathrm{al}^{19}$ showed that serum NOx may be used as a potential prognostic marker of DHF in patients presenting with DF in the early stage (on day 3 of fever) of the disease.

Since our sample size was small, further studies on these proteins are needed to better understand the cellular response to dengue virus infection and for the identification and validation of predictive biomarkers of severe dengue fever which would help to develop new diagnostic tools for early and timely detection of severe dengue infection.

\section{CONCLUSION}

In present study revealed that validating 26 serum samples used for optimization by using selected reaction monitoring. Three significant proteins, CD44 Antigen, Complement component C8 beta chain, Leucine-rich alpha-2-glycoprotein are downregulated in severe dengue (DHF/DSS) patients as compared to healthy controls. These are predictive biomarkers of severe dengue fever (DHF/DSS).

Since our sample size was small in number, further studies on these large sample size are needed to better understand the cellular response to dengue virus infection and validation of predictive biomarker of severe dengue fever which would help to develop new diagnostic tools for early detection of severity.

Table 1 Distribution of cases according to dengue agglutination test

\begin{tabular}{|c|c|c|c|c|c|c|c|c|}
\hline Dengue & \multicolumn{2}{|c|}{ DHF } & \multicolumn{2}{c|}{ DSS } & \multicolumn{2}{|c|}{ Total } & \multirow{2}{*}{$\boldsymbol{X}^{2}$} & p \\
\cline { 2 - 9 } Agglutination Test & No. & \% & No. & \% & No. & \% & & \\
\hline IgM & 21 & 100 & 5 & 100 & 26 & 100 & - & - \\
\hline IgG & 0 & - & 0 & - & 0 & - & - & - \\
\hline NS1 & 15 & 71.4 & 3 & 60.0 & 18 & 69.2 & 0.248 & 0.619 \\
\hline
\end{tabular}

Table 2 Distribution of cases according to clinical manifestation

\begin{tabular}{|c|c|c|c|c|c|c|c|c|}
\hline $\begin{array}{c}\text { Clinical } \\
\text { Manifestations }\end{array}$ & \multicolumn{2}{|c|}{ DHF } & \multicolumn{2}{|c|}{ DSS } & \multicolumn{2}{|c|}{ Total } & \multirow{2}{*}{$\boldsymbol{X}^{\mathbf{2}}$} & p \\
\cline { 2 - 9 } & No. & $\mathbf{\%}$ & No. & $\mathbf{\%}$ & No. & $\mathbf{\%}$ & & \\
\hline Fever & 21 & 100 & 5 & 100 & 26 & 100 & - & - \\
\hline Abdominal Pain & 21 & 100 & 5 & 100 & 26 & 100 & - & - \\
\hline Myalgia & 21 & 100 & 5 & 100 & 26 & 100 & - & - \\
\hline Rash & 20 & 95.2 & 5 & 100 & 25 & 96.2 & 0.248 & 0.619 \\
\hline Vomiting & 19 & 90.5 & 5 & 100 & 24 & 92.3 & 0.516 & 0.473 \\
\hline Headache & 19 & 90.5 & 5 & 100 & 24 & 92.3 & 0.516 & 0.473 \\
\hline Retro-orbital Pain & 18 & 85.7 & 5 & 100 & 23 & 88.5 & 0.807 & 0.369 \\
\hline
\end{tabular}

Table 3 Distribution of cases according to bleeding manifestations

\begin{tabular}{|c|c|c|c|c|c|c|c|c|}
\hline Bleeding & \multicolumn{2}{|c|}{ DHF } & \multicolumn{2}{|c|}{ DSS } & \multicolumn{2}{c|}{ Total } & \multirow{2}{*}{$\boldsymbol{X}^{2}$} & p \\
\cline { 2 - 9 } Manifestations & No. & $\mathbf{\%}$ & No. & $\mathbf{\%}$ & No. & $\mathbf{\%}$ & & \\
\hline Gum Bleeding & 19 & 90.5 & 5 & 100 & 24 & 92.3 & 0.516 & 0.473 \\
\hline Epistaxis & 14 & 66.7 & 4 & 80.0 & 18 & 69.2 & 0.337 & 0.562 \\
\hline Petechiae & 11 & 52.4 & 3 & 60.0 & 14 & 53.8 & 0.094 & 0.759 \\
\hline Hematuria & 7 & 33.3 & 2 & 40.0 & 9 & 34.6 & 0.292 & 0.864 \\
\hline Hematemesis & 3 & 14.3 & 2 & 40.0 & 5 & 19.2 & 1.857 & 0.395 \\
\hline Melena & 2 & 9.5 & 0 & - & 2 & 7.7 & 0.516 & 0.473 \\
\hline Purpura & 0 & - & 0 & - & 0 & - & - & - \\
\hline $\begin{array}{c}\text { Subconjunctival } \\
\text { Haemorrhage }\end{array}$ & 0 & - & 0 & - & 0 & - & - & - \\
\hline
\end{tabular}

Table 4 Distribution of cases according to sensorium

\begin{tabular}{|c|c|c|c|c|c|c|}
\hline \multirow[t]{2}{*}{ Sensorium } & \multicolumn{2}{|c|}{ DHF } & \multicolumn{2}{|c|}{ DSS } & \multicolumn{2}{|c|}{ Total } \\
\hline & No. & $\%$ & No. & $\%$ & No. & $\%$ \\
\hline Altered & 1 & 4.8 & 0 & - & 1 & 3.8 \\
\hline Normal & 20 & 95.2 & 5 & 100 & 25 & 96.2 \\
\hline Total & 21 & 100 & 5 & 100 & 26 & 100 \\
\hline$X^{2}$ & \multicolumn{4}{|c|}{0.248} & & \\
\hline $\mathrm{p}$ & \multicolumn{4}{|c|}{0.619} & & \\
\hline
\end{tabular}

Table 5 Distribution of cases according to haemoglobin

\begin{tabular}{|c|c|c|c|c|c|c|}
\hline Haemoglobin & \multicolumn{2}{|c|}{ DHF } & \multicolumn{2}{c|}{ DSS } & \multirow{2}{*}{ p } & \multirow{2}{*}{} \\
\cline { 2 - 5 } & Mean & SD & Mean & SD & & \\
\hline Day 1 & 7.56 & 0.34 & 8.32 & 0.48 & 3.288 & 0.003 \\
\hline Day 2 & 7.68 & 0.31 & 8.52 & 0.45 & 3.885 & 0.001 \\
\hline Day 3 & 7.96 & 1.40 & 8.76 & 0.41 & 4.231 & $<0.001$ \\
\hline Day 4 & 8.18 & 0.13 & 8.97 & 0.43 & 4.029 & $<0.001$ \\
\hline
\end{tabular}


Volume - 10 | Issue - 8 | August - 2020 | PRINT ISSN No. 2249 - 555X | DOI : 10.36106/ijar

Table 6 Distribution of cases according to outcome

\begin{tabular}{|c|c|c|c|c|c|c|}
\hline \multirow[t]{2}{*}{ Outcome } & \multicolumn{2}{|c|}{ DHF } & \multicolumn{2}{|c|}{ DSS } & \multicolumn{2}{|c|}{ Total } \\
\hline & No. & $\%$ & No. & $\%$ & No. & $\%$ \\
\hline Cured & 15 & 71.4 & 5 & 100 & 20 & 76.9 \\
\hline Discharge on Request & 6 & 28.6 & 0 & - & 6 & 23.1 \\
\hline Total & 21 & 100 & 5 & 100 & 26 & 100 \\
\hline$X^{2}$ & \multicolumn{4}{|c|}{1.857} & & \\
\hline $\mathrm{P}$ & \multicolumn{4}{|c|}{0.173} & & \\
\hline
\end{tabular}

Table 7

\begin{tabular}{|c|c|c|c|c|c|}
\hline S.no. & Protein ID & Protein name & HC & DHF/DSS & FC \\
\hline 1 & P16070 & CD44 antigen & 2.684922 & 2.651115 & 0.987409 \\
\hline 2 & P07358 & $\begin{array}{c}\text { Complement } \\
\text { component C8 } \\
\text { beta chain }\end{array}$ & 5.307983 & 5.240276 & 0.987244 \\
\hline 3 & P02750 & $\begin{array}{c}\text { Leucine-rich } \\
\text { alpha-2- } \\
\text { glycoprotein }\end{array}$ & 7.421469 & 7.303648 & 0.984124 \\
\hline
\end{tabular}

Table 8 List of proteins taken for optimization of the SRM assay

\begin{tabular}{|c|c|c|}
\hline sp|P02750|A2GL HUMAN & Leucine-rich alpha-2-glycoprotein $\mathrm{OS}=$ Homo sapiens $\mathrm{OX}=9606 \mathrm{GN}=\mathrm{LRG} 1 \mathrm{PE}=1 \mathrm{SV}=2$ & P02750 \\
\hline sp|P04004|VTNC_HUMAN & Vitronectin $\mathrm{OS}=$ Homo sapiens $\mathrm{OX}=9606 \mathrm{GN}=\mathrm{VTN} \mathrm{PE}=1 \mathrm{SV}=1$ & P04004 \\
\hline sp $\mid$ P00738|HPT HUMAN & Haptoglobin $\mathrm{OS}=$ Homo sapiens $\mathrm{OX}=9606 \mathrm{GN}=\mathrm{HP} \mathrm{PE}=1 \mathrm{SV}=1$ & P00738 \\
\hline sp|Q08380|LG3BP HUMAN & -3-binding protein $\mathrm{OS}=$ Homo sapiens $\mathrm{OX}=9606 \mathrm{GN}=\mathrm{LGALS} 3 \mathrm{BP} \mathrm{PE}=1 \mathrm{SV}=1$ & Q08380 \\
\hline sp|P0DJI8|SAA1_HUMAN & Serum amyloid A-1 protein OS=Homo sapiens $\mathrm{OX}=9606 \mathrm{GN}=\mathrm{SAA} 1 \mathrm{PE}=1 \mathrm{SV}=1$ & P0DJI8 \\
\hline sp|P17936|IBP3_HUMAN & $\begin{array}{l}\text { Insulin-like growth factor-binding protein } 3 \mathrm{OS}=\text { Homo sapiens } \mathrm{OX}=9606 \mathrm{GN}=\mathrm{IGFBP3} \mathrm{PE}=1 \\
\mathrm{SV}=2\end{array}$ & P17936 \\
\hline $\operatorname{tr|D6RF35|D6RF35~HUMAN~}$ & Vitamin D-binding protein $\mathrm{OS}=$ Homo sapiens $\mathrm{OX}=9606 \mathrm{GN}=\mathrm{GC} \mathrm{PE}=1 \mathrm{SV}=1$ & D6RF35 \\
\hline sp|P49747|COMP HUMAN & age oligomeric matrix protein $\mathrm{OS}=$ Homo sapiens $\mathrm{OX}=9606 \mathrm{GN}=\mathrm{COMP} \mathrm{PE}=1 \mathrm{SV}=2$ & P49747 \\
\hline sp|P01023|A2MG_HUMAN & Alpha-2-macroglobulin $\mathrm{OS}=$ Homo sapiens $\mathrm{OX}=9606 \mathrm{GN}=\mathrm{A} 2 \mathrm{M} \mathrm{PE}=1 \mathrm{SV}=3$ & P01023 \\
\hline sp|P10909|CLUS HUMAN & Clusterin $\mathrm{OS}=$ Homo sapiens $\mathrm{OX}=9606 \mathrm{GN}=\mathrm{CLU} \mathrm{PE}=1 \mathrm{SV}=1$ & P10909 \\
\hline sp|P02647|APOA1_HUMAN & Apolipoprotein A-I OS=Homo sapiens OX=9606 GN=APOA1 PE=1 SV=1 & P02647 \\
\hline sp|P06396|GELS_HUMAN & Gelsolin OS=Homo sapiens $\mathrm{OX}=9606 \mathrm{GN}=\mathrm{GSN} \mathrm{PE}=1 \mathrm{SV}=1$ & P06396 \\
\hline sp|P09871|C1S HUMAN & Complement $\mathrm{C} 1$ s subcomponent $\mathrm{OS}=$ Homo sapiens $\mathrm{OX}=9606 \mathrm{GN}=\mathrm{C} 1 \mathrm{~S} \mathrm{PE}=1 \mathrm{SV}=1$ & P09871 \\
\hline sp|P00450|CERU HUMAN & Ceruloplasmin OS $=$ Homo sapiens $\mathrm{OX}=9606 \mathrm{GN}=\mathrm{CP} \mathrm{PE}=1 \mathrm{SV}=1$ & P00450 \\
\hline sp|P04180|LCAT_HUMAN & ferase $\mathrm{OS}=$ Homo sapiens $\mathrm{OX}=9606 \mathrm{GN}=\mathrm{LCAT} \mathrm{PE}=1 \mathrm{SV}=1$ & P04180 \\
\hline sp|P07358|CO8B HUMAN & chain $\mathrm{OS}=$ Homo sapiens $\mathrm{OX}=9606 \mathrm{GN}=\mathrm{C} 8 \mathrm{~B} \mathrm{PE}=1 \mathrm{SV}=3$ & $\mathrm{P} 07358$ \\
\hline sp|Q9UGM5|FETUB HUMAN & piens $\mathrm{OX}=9606 \mathrm{GN}=\mathrm{FETUB} \mathrm{PE}=1 \mathrm{SV}=2$ & Q9UGM5 \\
\hline sp|O75636|FCN3_HUMAN & Ficolin $-3 \mathrm{OS}=$ Homo sapiens $\mathrm{OX}=9606 \mathrm{GN}=\mathrm{FCN} 3 \mathrm{PE}=1 \mathrm{SV}=2$ & O75636 \\
\hline sp|P01008|ANT3 HUMAN & Antithrombin-III OS=Homo sapiens OX=9606 GN=SERPINC1 $\mathrm{PE}=1 \mathrm{SV}=1$ & P01008 \\
\hline sp|P02760|AMBP_HUMAN & Protein AMBP OS=Homo sapiens $\mathrm{OX}=9606 \mathrm{GN}=\mathrm{AMBP} \mathrm{PE}=1 \mathrm{SV}=1$ & $\mathrm{P} 02760$ \\
\hline sp|P19320|VCAM1_HUMAN & Vascular cell adhesion protein $1 \mathrm{OS}=$ Homo sapiens $\mathrm{OX}=9606 \mathrm{GN}=\mathrm{VCAM} 1 \mathrm{PE}=1 \mathrm{SV}=1$ & P19320 \\
\hline sp|P16070|CD44 HUMAN & CD44 antigen $\mathrm{OS}=$ Homo sapiens $\mathrm{OX}=9606 \mathrm{GN}=\mathrm{CD} 44 \mathrm{PE}=1 \mathrm{SV}=3$ & P16070 \\
\hline sp|Q9NZP8|C1RL_HUMAN & otein $\mathrm{OS}=$ Homo sapiens $\mathrm{OX}=9606 \mathrm{GN}=\mathrm{C} 1 \mathrm{RL} \mathrm{PE}=1 \mathrm{SV}=2$ & Q9NZP8 \\
\hline sp|P02747|C1QC_HUMAN & Complement C1q subcomponent subunit $\mathrm{C} \mathrm{OS}=$ Homo sapiens OX=9606 GN=C1QC PE=1 SV=3 & $\mathrm{P} 02747$ \\
\hline sp|P25311|ZA2G HUMAN & $=$ Homo sapiens $\mathrm{OX}=9606 \mathrm{GN}=\mathrm{AZGP} 1 \mathrm{PE}=1 \mathrm{SV}=2$ & P25311 \\
\hline sp|P04217|A1BG_HUMAN & Alpha-1B-glycoprotein $\mathrm{OS}=$ Homo sapiens $\mathrm{OX}=9606 \mathrm{GN}=\mathrm{A} 1 \mathrm{BG} \mathrm{PE}=1 \mathrm{SV}=4$ & P04217 \\
\hline
\end{tabular}

\section{REFERENCES}

1. Halstead SB, Suaya JA, Shepard DS. The burden of dengue infection. Lancet 2007;369:1410-1411

2. Wu SJ, Grouard-Vogel G, Sun W, Mascola JR, Brachtel E, et al. Human skin Langerhans cells are targets of dengue virus infection. Nat Med 2000; 6: 816-820.

3. Guzman MG, Kouri G. Dengue : An Update. Lancet Infect Dis 2002;2:33-42.

4. World Health Organization. First report on neglected tropical diseases: working to overcome the global impact of neglected tropical diseases. Geneva: World Health overcome the global
Organization; 2010 .

5. World Health Organization. Comprehensive guidelines for prevention and control of dengue and dengue hemorrhagic fever. New Delhi: WHO, SEARO; 2011: revised and expanded edition.

6. Chen YY, Lin SY, Yeh YY, Hsiao HH, Wu CY, Chen ST, Wang AHJ. A modified protein precipitation procedure for efficient removal of albumin from serum. Electrophoresis. 2005;26(11):2117-2127.

7. Clark DV, Mammen MP, Nisalak A, Puthimethee V, Endy TP. Economic impact of dengue fever/dengue haemorrhagic fever in Thailand at the family and population dengue fever/dengue haemorrhagic fever in Thailand at the family and population
levels. The American journal of tropical medicine and hygiene. 2005;1:72(6):786-91.

8. Suaya JA, Shepard DS, Siqueira JB, Martelli CT, Lum LC, et al. Cost of dengue cases in eight countries in the Americas and Asia: a prospective study. Am J Trop Med Hyg 2009; $80: 846-855$.

9. Chinna RS, Goyal O, Chhina D. Liver function test in patients with dengue viral infection. Dengue Bull 2008; 32:346.

10. Kumar S, Bhandiwad C, Lakhiwal R, Singh CP, Sharma N, Chhimpa A. Study of dengue outbreak in North West zone of Rajasthan, India. Int J Res Med Sci 2018;6(9)2905-8.

11. Laul A, Laul P, Merugumala V, Pathak R, Miglani U, Saxena P. Clinical profiles of dengue infection during an outbreak in Northern India. J Trop Med 2016; 5917934.

12. Zhang H, Zhou YP, Peng HJ, Zhang XH, Zhou FY, Liu ZH, Chen XG. Predictive symptoms and signs of sevee dengue disease for patients with dengue fever:A meta analysis. Bio Med Res Int 2014; 359308 .

13. Mehrotra S, Singh M, Kumar A, Misra R. Hematological parameters in dengue fever. Int JAdvanc Res 2018; 6(3):1247-54.

14. Khurram M, Qayyum W, Umar M, Jawad M, Mumtaz S, Khaar HTB. Ultrasonographic pattern of plasma leak in dengue haemorrhagic fever. J Pak Med Assoc 2016;260-4.

15. Jadhav M, Nayak M, Kumar S, Venkatesh A, Patel SK, Kumar V. Clinical Proteomics and Cytokine Profiling for Dengue Fever Disease Severity Biomarkers. OMICS. 2017; 21(11):665-677.

16. Lin CY, Kolliopoulos C, Huang CH, Tenhunen J, Heldin CH, Chen YH et al. High levels of seumhyaluronan is an early predictor of dengue warning signs and perturbs vascular integrity. E Bio Med 2019; 48L425-441.

17. Flores-Mendoza LK, Estrada-Jimenez T, Sedeno-Monge V, Moreno M, Manjarrez MDC et al. IL-10 and socs3 are predictive biomarkes of dengue hemorrhagic fever. Medications of Inflammation 2017;2017: 5197592.

18. Manchala NR, Dungdung R, Pilankatta R. Proeomic analysis reveals the enhancement of human serum apolipoprotein A-1 (APO-1) in individuals infected with multiple dengue virus serotypes. Trop Med IntHlth 2017; 22(10):1334-42.

19. Mapalagamage M, Handunnetti S, Premawansa G, Thillainathan S, Fernando T, KanapathippillaiK et al. Is total serum nitric and nitrate (NOx) level in dengue patients a potential prognostic marker of dengue hemorrhagic fever? Dis Mar 2018; 5328681:9. 